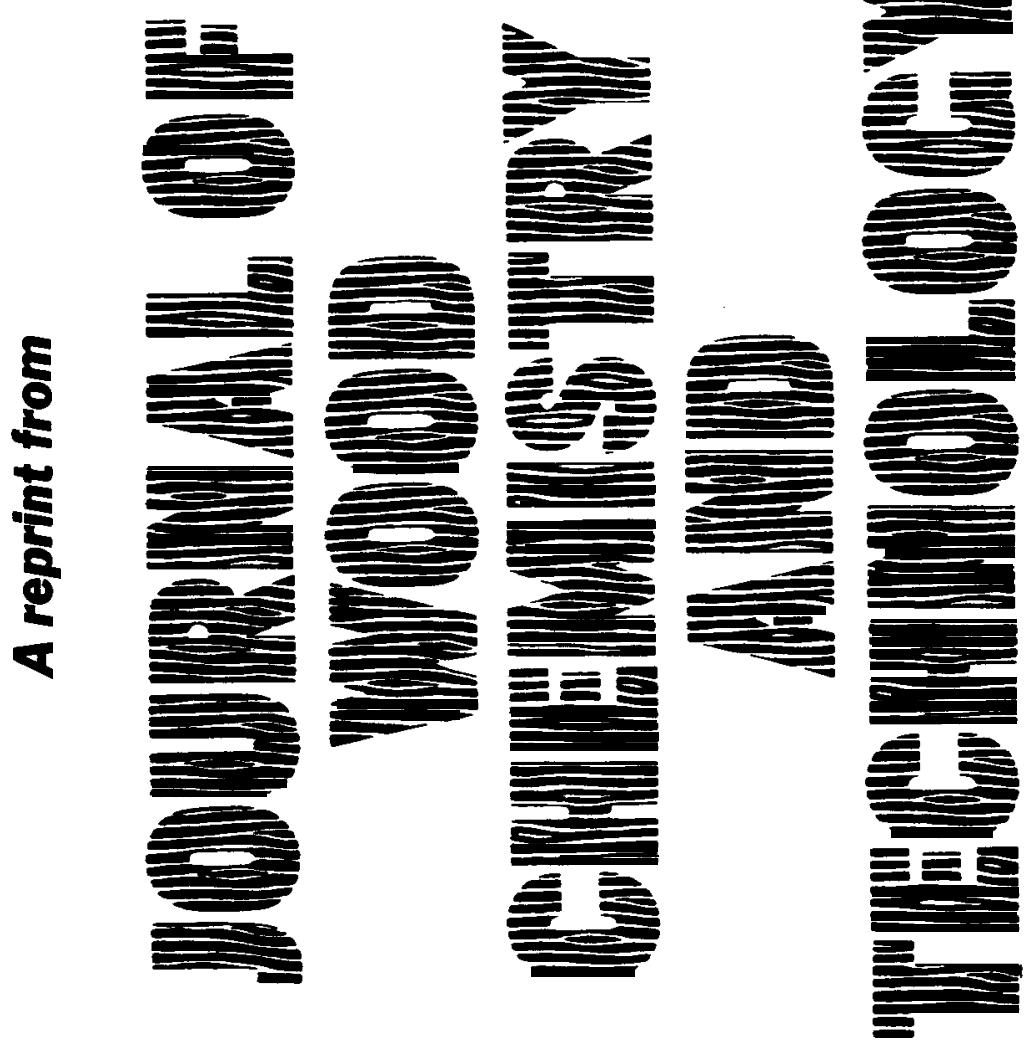




\section{Journal of Wood Chemistry and Technology}

Over the past few years, research activities aimed at increasing the utility of one of our most important natural resources, wood, have grown enormously. Yet existing journals have not been wholly successful at keeping pace with new developments, with the result that that scientists in need of a key journal that highlights major new contributions have, instead, had to cope with a plethora of tangential sources.

Focusing exclusively on the chemistry of wood, wood components, and wood products, the Journal of Wood Chemistry and Technology fills this need of researchers by presenting comprehensive, upto-date coverage of investigations that add new understanding to chemical phenomena important to wood technology. In each issue, some of the most active and innovative researchers in their respective specialties present their latest work on such topics as new approaches and insights into the chemistry of pulping; lignin, cellulose, hemicellulose, and extractives chemistry; chemicals derived from wood and bark and their isolation; wood bonding; and biomass conversion and utilization. Reviewed by an editorial board composed of internationally renowned researchers in the field, the articles in the Journal of Wood Chemistry and Technology are of great value to wood chemists, cellulose and lignin chemists, chemical engineers, wood technologists, research scientists and engineers, process engineers, physical chemists, and biologists.

With its complete coverage and its rapid lab-to-print format, the Journal of Wood Chemistry and Technology presents scientists with a sharply focused, eminently useful source of practical, informative material that is of great value to a wide range of research and applied endeavors.

For subscription information write to:

Promotion Department

Marcel Dekker, Inc.

270 Madison Avenue

New York, N.Y. 10016 


\title{
PHENOLATION OF (+)-CATECHIN WITH MINERAL ACIDS. II. IDENTIFICATION OF NEW REACTION PRODUCTS
}

\author{
Weiling Peng and Anthony H. Conner \\ USDA-Forest Service \\ Forest Products Laboratory \\ Madison, WI 53705
}

and

Richard W. Hemingway

USDA-Forest Service

Southern Research Station

Pineville, LA 71360

\begin{abstract}
$\underline{\text { ABSTRACT }}$
To investigate the reactions that occur in the flavanoid unit during the liquefaction of tannin in phenol, the phenolysis of (+)-catechin was studied using either $\mathrm{H}_{2} \mathrm{SO}_{4}, \mathrm{HCl}$, or $\mathrm{BF}_{3} \cdot 2 \mathrm{H}_{2} \mathrm{O}$ as acid catalyst. In addition to 2-[3-(3,4-dihydroxyphenyl)-2-hydroxy-3-(4-hydroxyphenyl)propyl]-1,3,5benzenetriol (1) and 2-[(3,4-dihydroxyphenyl)(4-hydroxyphenyl)methyl]2,3-dihydro-4,6-benzofurandiol (3) that have been described previously, eight additional reaction products were isolated, four of which were compounds that have not been described previously. The novel compounds described here are: 2-[3-(3,4-dihydroxyphenyl)-2-hydroxy-3(2-hydroxyphenyl)propyl]-1,3,5-benzenetriol (2), 2-[(3,4-dihydroxyphenyl)(2-hydroxyphenyl)methyl]-2,3-dihydro-4,6-benzofurandiol (4), 2-[(3,4-dihydroxyphenyl)(4-hydroxyphenyl)methyl]-2,3-dihydro-7-(4hydroxyphenyl)methyl-4,6-benzofurandiol (5), and 2-(1,3,5-trihydroxyphenyl)methyl-3-(3,4-dihydroxyphenyl)-6-[(3,4-dihydroxyphenyl)(4hydroxyphenyl)methyl]-2,3,5,6-tetrahydrobenzo[1,2-b:5,4-b']-difuran-4-ol (6). The structures of these and other previously described
\end{abstract}


products are consistent with opening of the pyran ring of catechin and reaction at C-2 by either the para or the ortho position of phenol.

Additional products resulting from reaction between pyran ring cleavage products and catechin, and from reaction of cleavage products were found. Similar reactions would be expected to take place during the phenolysis of condensed tannins.

\section{INTRODUCTION}

Condensed tannins (polyflavanoids) and importantly, even whole bark, can be "liquefied" in phenol with an acid catalyst. The product can be used directly, without isolating the tannin by extraction from the bark, to partially replace phenol in the formulation of wood adhesives. ${ }^{1-3}$ Better understanding of the reactions that take place between phenol and tannin is needed in order to assess the applicability of the phenolation of bark tannins for use in adhesives to bond wood.

(+)-Catechin serves as a model compound for reactions because it is representative of the repeating units in tannins isolated from most conifer tree barks. ${ }^{1-3}$ Mitsunaga and his coworkers ${ }^{4-6}$ conducted pioneering studies on the reactions of catechin with phenol in benzene and xylene solvents using $\mathrm{BF}_{3}$ as the catalyst. Their results showed that highest yields of products were formed when benzene was added as an additional solvent. We observed that catechin and its phenolated products did not dissolve well when benzene or xylene were used as the solvent. ${ }^{7}$ In these reactions, large amounts of solids were suspended in the reaction solution, even after a reaction time of $240 \mathrm{~min}$ at $40{ }^{\circ} \mathrm{C}$. To come closer to a commercially viable process, our experiments ${ }^{7}$ were primarily directed to use of phenol both as a reactant and as the solvent in reactions catalyzed with mineral acids.

\section{RESULTS AND DISCUSSION}

TLC of the products formed after a 30 min reaction time at $40{ }^{\circ} \mathrm{C}$ using xylene as an additional solvent ${ }^{7}$ contained a spot at $R_{f}=0.42$ that was identified as catechin by its intense pink color after spraying with 
vanillin- $\mathrm{HCl}$ and from its NMR spectral properties. When no additional solvent was used, no suspended solids were observed and catechin was not detected among the reaction products even after only 20-30 min of reaction at $40{ }^{\circ} \mathrm{C}$ using either $\mathrm{H}_{2} \mathrm{SO}_{4}$ or $\mathrm{HCl}$ as the acid catalyst. The distribution of products, as evidenced by TLC, from reactions using benzene or no additional solvent were similar to those using xylene as solvent. ${ }^{7}$ However, in those cases where either benzene or no additional solvent (30 min reaction time) is used, the spot observed on TLC plates at $\mathbf{R}_{\mathrm{f}}=0.42$ was orange rather than pink after reaction with vanillin- $\mathrm{HCl}$. Therefore, this product ( 1 ) was isolated and its structure was studied.

The proton (Table 1) and carbon (Table 2) assignments for the propyl moiety in 1 were determined from a H-C HETCOR experiment that showed the two methylene protons $(\mathrm{H}-\mathrm{I})$ at $2.42 \mathrm{ppm}(1 \mathrm{H}, \mathrm{dd}, \mathrm{J}=10.0$ and $14.3 \mathrm{~Hz})$ and $2.96(1 \mathrm{H}, \mathrm{dd}, \mathrm{J}=1.9$ and $14.3 \mathrm{~Hz})$ were correlated with the carbon $(\mathrm{C}-\mathrm{I})$ resonance at $30.5 \mathrm{ppm}$; the proton $(\mathrm{H}-2)$ at $4.38 \mathrm{ppm}$ $(1 \mathrm{H}, \mathrm{m})$ was correlated with the carbon $(\mathrm{C}-2)$ resonance at $76.8 \mathrm{ppm}$; and the proton $(\mathrm{H}-3)$ at $3.77(1 \mathrm{H}, \mathrm{d}, \mathrm{J}=8.0 \mathrm{~Hz})$ was correlated with the carbon (C-3) resonance at $58.7 \mathrm{ppm}$. The comparatively large $\mathrm{J}_{2,3}$ coupling (8 Hz) indicates trans-stereochemistry.

The H-C HETCOR spectrum also showed that the proton signals at $6.69,6.70$, and $6.78 \mathrm{ppm}$ are correlated with the carbon signals at 120.9, 115.9 , and $116.8 \mathrm{ppm}$, respectively. The chemical shifts and the correlations between these signals are consistent with the catechol B-ring. However, measurement of coupling constants for the B-ring $A B X$ system (expected coupling $\mathrm{J}_{2,6}=$ about $2 \mathrm{~Hz}$ and $\mathrm{J}_{5.6}=$ about $8 \mathrm{~Hz}$ ) was complicated by overlap with the two proton doublet (6.72 ppm) assigned to $\mathrm{H}-3 / \mathrm{H}-5$ of the 4-hydroxyphenyl C-ring.

A COSY experiment showed that the $\mathrm{H}-3 / \mathrm{H}-5 \mathrm{C}$-ring aromatic protons at $6.72 \mathrm{ppm}(2 \mathrm{H}, \mathrm{d}, \mathrm{J}=8.6 \mathrm{~Hz})$ were correlated with the protons at 7.20 ppm $(2 \mathrm{H}, \mathrm{d}, \mathrm{J}=8.6 \mathrm{~Hz})$ assigned to $\mathrm{H}-2 / \mathrm{H}-6$ of the C-ring. Assignment of the protons at 6.72 and $7.20 \mathrm{ppm}$ to the 4-hydroxyphenyl C-ring was consistent with the fact that these protons were correlated with carbon resonances at 130.6 and $115.4 \mathrm{ppm}$ that could be assigned to C-2/C-6 and C-3/C-5, respectively. ${ }^{8}$ Symmetry in these signals shows that the phenol group is attached para to the 4-hydroxyl. 
The protons with a chemical shift of $5.89 \mathrm{ppm}(\mathrm{H}-4 / \mathrm{H}-6$ of the A-ring) are correlated with the carbon resonance at $96.0 \mathrm{ppm}$. These data are consistent with the symmetrical nature of the freely rotating phloroglucinolic A-ring.

A long range $\mathrm{H}-\mathrm{C}$ COLOC experiment (optimized for $\mathrm{J}_{\mathrm{CH}}$ of $5 \mathrm{~Hz}$ coupling) showed that the doublet (3.77 ppm), previously assigned to $\mathrm{H}-3$ of the propyl moiety, was correlated with signals previously assigned to C-I, C-2, and C-6 of the B-ring; to C-I, C-2, and C-6 of the 4-hydroxyphenyl ring; and to $\mathrm{C}-3$ and $\mathrm{C}-2$ of the propyl moiety. These data verify the location of the phenol substituent. These NMR data confirmed that this compound is 2-[3-(3,4-dihydroxyphenyl)-2-hydroxy-3-(4-hydroxyphenyl)propyl]-1,3,5-benzenetriol(1), a product described previously by Mitsunaga et al. ${ }^{4-6}$

A second product (2) with slightly higher $R_{f}$ value was purified from this reaction. The proton (Table 1) and carbon (Table 2) NMR spectra of 2 were very similar to those of the previously described compound. Assignment of the propyl moiety, the phloroglucinolic A-ring, and the catecholic B-ring were determined from data similar to that described above. The coupling constant of $6.8 \mathrm{~Hz}$ for $\mathrm{J}_{2.3}$ of the propyl moiety is consistent with trans-stereochemistry. The four aromatic protons at 6.62 and $7.31 \mathrm{ppm}$ that are assigned to the ortho-substituted hydroxyphenyl C-ring (Table 1) were correlated with carbon resonances at 116.0, 128.2, 121.1 and $131.6 \mathrm{ppm}$ through a H-C HETCOR experiment. The chemical shifts of these four carbons are very close to those calculated ${ }^{8}$ for the four corresponding carbons of an ortho-substituted phenol: 115.7, 127.0, 121.1 , and 130.6. Thus, the NMR data is consistent with a structure for 2 that is an ortho-substituted regio-isomer of 1 , namely 2-[3-(3,4-dihydroxyphenyl)-2-hydroxy-3-(2-hydroxyphenyl)propyl]-1,3,5-benzenetriol (2). The mass spectral data are also consistent with the proposed structure for this novel compound.

Compound 3, 2-[(3,4-dihydroxyphenyl)(4-hydroxyphenyl)methyl]-2,3dihydro-4,6-benzofurandiol, was previously isolated after phenolysis of catechin and its structure determined by Mitsunaga et al. ${ }^{4-6}$ This compound was also isolated from reactions of catechin in phenol with a mineral acid catalyst. ${ }^{7}$ The proton (Table 1) and carbon (Table 2) NMR 


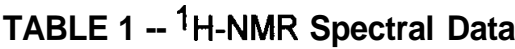 \\ Compound}

\begin{tabular}{|c|c|c|c|c|c|c|c|}
\hline \multirow{2}{*}{$\begin{array}{l}\text { Moiety/ } \\
\text { Ring }\end{array}$} & \multicolumn{7}{|c|}{ 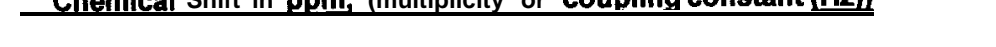 } \\
\hline & Positio & on 1 & 2 & 3 & 4 & 5 & 6 \\
\hline $\mathbf{A}$ & 4:5:5:3a & $5.69(s)$ & $5.85(\mathrm{~s})$ & $5.86(2.0)$ & $5.87(1.9)$ & $5.88(s)$ & $6.01(s)$ \\
\hline A & $6: 7:-: 5^{a}$ & $5.89(s)$ & $5.85(\mathrm{~s})$ & $5.74(2.0)$ & $5.76(1.9)$ & & $6.01(s)$ \\
\hline $\mathbf{B}$ & 2 & $-6.78 \mathrm{~b}$ & $-6.80 \mathrm{~b}$ & $6.84(2.0)$ & $6.92(1.9)$ & $6.77(1.9)$ & $6.36(2.0)$ \\
\hline B & 5 & $\sim 6.70^{b}$ & $\sim 6.78^{b}$ & $6.77(9.6)$ & $6.79(8.0)$ & $6.73(8.2)$ & $6.58(8.1)$ \\
\hline B & 6 & $-6.69 b$ & $\sim 6.76^{b}$ & $6.72(2.0,9.6)$ & $6.77(1.9,8.0)$ & )6.65(1.9,8.0 & $6.19(2.0,8.1)$ \\
\hline cc & 2 & & & $5.44(\mathrm{~m})$ & $5.61(\mathrm{~m})$ & $5.30(\mathrm{~m})$ & $4.78(\mathrm{~m})$ \\
\hline $\mathrm{cc}^{\mathrm{C}}$ & 3 & & & & & & $4.34(3.4)$ \\
\hline cc & $3 a$ & & & $2.70(7.9,15)$ & $2.78(7.9,15)$ & $2.75(8.5,14$ & \\
\hline cc & $3 b$ & & & $2.96(8.8,15)$ & $2.97(8.9,15)$ & $2.98(7.0,14$ & 3) \\
\hline C:D:Fd & 2 & $7.20(8.6)$ & & $7.22(6.5)$ & & $7.09(8.6)$ & $7.24(8.7)$ \\
\hline$C / D / F d$ & 3 & $6.72(8.6)$ & $6.62(8.2)$ & $6.75(6.5)$ & $6.75(8.1)$ & $6.69(8.6)$ & $-6.77(8.7)$ \\
\hline$C / D / F d$ & 4 & & 7.02(m) & & $7.00(m)$ & & \\
\hline$C / D / F d$ & 5 & $6.72(8.6)$ & $6.67(\mathrm{~m})$ & $6.75(6.5)$ & $6.82(\mathrm{~m})$ & $6.69(8.6)$ & $-6.77(8.7)$ \\
\hline $\mathrm{C} / \mathrm{D} / \mathrm{Fd}^{\mathrm{d}}$ & 6 & $7.20(8.6)$ & $7.31(6.6)$ & $7.22(6.5)$ & $7.50(7.7)$ & $7.09(8.6)$ & $7.24(8.7)$ \\
\hline D & 6 & & & & & & $5.75(s)$ \\
\hline E & 3 & & & & & & $6.61(8.5)$ \\
\hline E & $5 \mathbf{a}$ & & & & & & $2.71(7.9,15.0)$ \\
\hline E & $5 b$ & & & & & & $-3.00 \mathrm{e}$ \\
\hline E & $6-$ & & & & & & $5.44(\mathrm{~m})$ \\
\hline E/Gf & 2 & & & & $6.97(8.5)$ & $6.85(1.7)$ & \\
\hline EIGf & 5 & & & & $6.61(8.5)$ & $\sim 6.77(8.6)$ & \\
\hline E/Gf & 6 & & & & $6.97(8.5)$ & $6.75(1.7,8$ & \\
\hline Propyl & $1 \mathrm{a} 2$ & $2.42(10,14.3$ & 3) $2.43(9.8$ & $8,14.2)$ & & & \\
\hline Propyl & $\mathrm{lb}$ & $2.96(1.9,14$. & .3) $2.94(1.9$ & , 14.2) & & & \\
\hline Propyl & 2 & $4.38(\mathrm{~m})$ & $4.49(\mathrm{~m})$ & & & & \\
\hline Propyl & 3 & $3.77(8.0)$ & $4.28(6.8)$ & & & & \\
\hline a & & & & $3.96(9.4)$ & $4.54(9.5)$ & $3.85(8.8)$ & $3.99(9.7)$ \\
\hline$\beta a$ & & & & & & & $\sim 2.98{ }^{\circ}$ \\
\hline$\beta \mathbf{b}$ & & & & & & & $\sim 3.08 \theta^{\theta}$ \\
\hline$\beta$ & & & & & & $3.58(\mathrm{~m})$ & \\
\hline
\end{tabular}

a Numbers refer to compounds 1 and 2: 3 and 4; 5: and 6

b Coupling not determined because of overlapping peaks

C Furan C-rings in compounds $3,4,5$, and 6

d C-ring in compounds 1 and 2; D-rings in 3 and 4, F-ring in 6

e Proton signals obscured by solvent, assigned from HETCOR experiment

$f$ E-ring in compound 5 and G-ring in compound 6 


\section{TABLE 2 -- ${ }^{13}$ C-NMR Spectral Data}

\section{Ringl}

Moiety Position
Compound

Chemical shift in oom

\begin{tabular}{ccc}
\hline 1 & Chemicalshifin
\end{tabular}

456

\begin{tabular}{|c|c|c|c|c|c|c|c|}
\hline A & $2: 3 a: 1^{a}$ & 106.4 & 106.4 & 104. 4 & 104. 3 & 104. 9 & 104. 3 \\
\hline$A$ & $1: 4: 2^{a}$ & 158. 1 & 156. 2 & 159.5 & 155.7 & 152.6 & f 67.3 \\
\hline$A$ & $4: 5: 3^{a}$ & 66.0 & 66.0 & 95.6 & 95.8 & 66.0 & 64.6 \\
\hline$A$ & $5: 6: 4^{a}$ & 157. 5 & 156.7 & 162.6 & 162.9 & 161. 0 & 157.0 \\
\hline $\mathbf{A}$ & $6: 7: 5^{a}$ & 96.0 & 68.0 & 90.3 & 60.4 & 104.4 & 64.6 \\
\hline$A$ & $3: 7 a: 6^{a}$ & 158. 1 & 156. 2 & 155.6 & 155. 0 & 156. 4 & 157. 3 \\
\hline $\mathbf{B}$ & 1 & 136. 9 & 135. 6 & 135.5 & 134.7 & 136.4 & 134.1 \\
\hline B & 2 & 116. 6 & 117. 2 & 116. 9 & 116. 9 & 117. 4 & 113. 3 \\
\hline B & 3 & 144.3 & 144.3 & 144.5 & 144.4 & 144. 6 & 143. 6 \\
\hline B & 4 & 145. 6 & 145.8 & 145.8 & 146. 6 & 146. 0 & 145.0 \\
\hline B & 5 & 115.9 & 117.0 & 116.4 & 116.1 & 116. 9 & 114. 6 \\
\hline $\mathbf{B}$ & 6 & 120.9 & 120.6 & 120.5 & 121.1 & 121. 6 & 118.5 \\
\hline C & 1 & 135.5 & 130.2 & & & & \\
\hline $\mathrm{C}$ & 2 & 130.6 & 156.4 & 86.7 & 66.1 & 87.0 & 92.2 \\
\hline $\mathrm{C}$ & 3 & 115.4 & 116.0 & 32.5 & 32.4 & 32.9 & 46. 6 \\
\hline $\mathrm{C}$ & 4 & 156. 3 & 126. 2 & & & & \\
\hline C & 5 & 115. 4 & 121.1 & & & & \\
\hline C & 6 & 130.6 & 131. 6 & & & & \\
\hline D & 1 & & & 134. 9 & 130.3 & 136. 0 & \\
\hline $\mathbf{D}$ & 2 & & & 130. 2 & 159. 5 & 130.9 & \\
\hline D & 3 & & & 116. 0 & 116. 6 & 116.4 & \\
\hline D & $3 a$ & & & & & & 108. 0 \\
\hline D & 4 & & & 156. 5 & 127. 7 & 156. 7 & 150.4 \\
\hline D & $4 a$ & & & & & & 101.7 \\
\hline D & 5 & & & 116. 0 & 120.6 & 116.4 & \\
\hline D & 6 & & & 130.2 & 129.5 & 130.9 & \\
\hline D & $7 a$ & & & & & & 161.2 \\
\hline D & 6 & & & & & & 64.7 \\
\hline D & $8 a$ & & & & & & 161.5 \\
\hline$E$ & 1 & & & & & 135.1 & \\
\hline$E$ & $\overline{2}$ & & & & & 130.7 & \\
\hline$E$ & 3 & & & & & 116. 2 & \\
\hline$E$ & 4 & & & & & 155.7 & \\
\hline$E$ & 6 & & & & & 116. 2 & 31.8 \\
\hline$E$ & 6 & & & & & 130.7 & 86.1 \\
\hline $\boldsymbol{F}$ & 1 & & & & & & 136.5 \\
\hline $\boldsymbol{F}$ & 2 & & & & & & 126. 6 \\
\hline$F$ & 3 & & & & & & 115.1 \\
\hline $\mathrm{F}$ & 4 & & & & & & 155.7 \\
\hline $\mathrm{F}$ & 5 & & & & & & 115.1 \\
\hline $\mathrm{F}$ & 6 & & & & & & 126. 6 \\
\hline $\mathbf{G}$ & 1 & & & & & & 134.6 \\
\hline $\mathbf{G}$ & 2 & & & & & & 115. 6 \\
\hline $\mathbf{G}$ & 3 & & & & & & 143. 2 \\
\hline $\mathbf{G}$ & 4 & & & & & & 144.7 \\
\hline $\mathbf{G}$ & 5 & & & & & & 115. 2 \\
\hline $\mathbf{G}$ & 6 & & & & & & 119.7 \\
\hline Propyl & 1 & 30.5 & 30.7 & & & & \\
\hline Propyl & 2 & 76.6 & 77.0 & & & & \\
\hline \multirow[t]{3}{*}{ Propyl } & 3 & 56.7 & 53.2 & & & & \\
\hline & $\boldsymbol{\alpha}$ & & & 58. 3 & 49.4 & 56.6 & 55.4 \\
\hline & $\beta$ & & & & & 26.0 & 28.6 \\
\hline
\end{tabular}

${ }^{a}$ Numbers refer to compounds 1 and 2: compounds 3,4, and 5: and compound 6 


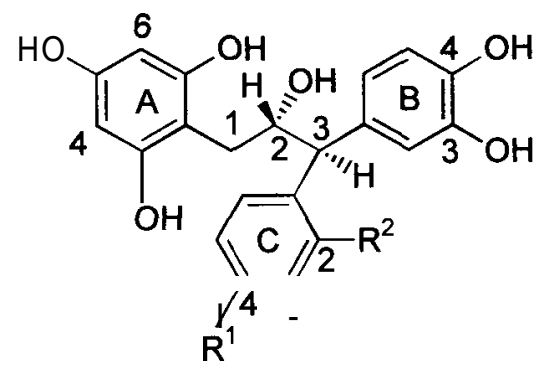

$$
\begin{aligned}
& I \mathbf{R}^{1}=O H ; \mathbf{R}^{2}=H \\
& 2 \mathbf{R}^{1}=H ; \mathbf{R}^{2}=O H
\end{aligned}
$$

spectra of 3 are similar to the corresponding spectra of 1 , indicating the presence of a p-hydroxyphenyl ring and of a catechol ring. Due to the presence of the dihydrobenzofuran ring, the phloroglucinol ring in 3 is not freely rotating and the aromatic protons of the phloroglucinol ring appear as two, meta-coupled doublets $(\mathrm{J}=\sim 2 \mathrm{~Hz})$ at 5.74 and $5.66 \mathrm{ppm}$. In addition, proton $\mathrm{H}-2$ of the propyl moiety that occurs at $4.38 \mathrm{ppm}$ in 1 shifts to $5.44 \mathrm{ppm}$ in 3 . The coupling constant of $9.4 \mathrm{~Hz}$ for $J_{2, \alpha}$ is consistent with trans-stereochemistry.

Assignment of the proton (Table 1) and carbon (Table 2) chemical shifts for the catechol B-ring and the o-hydroxyphenyl ring in 4, was accomplished by methods similar to those used for making assignments of 2. The aromatic proton doublets at 5.76 and $5.87 \mathrm{ppm}$ in 4 were assigned to the phloroglucinol ring by comparison with the NMR spectra of 3 . The mutiplet at $5.61 \mathrm{ppm}$ can be assigned to $\mathrm{H}-2$ of the furan ring by comparison with the corresponding chemical shift of a similar multiplet seen in the ${ }^{1} \mathrm{H}$-NMR spectrum of 3 . The coupling constant of $9.5 \mathrm{~Hz}$ for $J_{2, \alpha}$ is consistent with trans-stereochemistry between $\mathrm{H}-2$ of the furan ring and $\mathrm{H}-\mathrm{a}$. These data show that this compound is the novel orthosubstituted regio-isomer of 3 , namely, 2-[(3,4-dihydroxyphenyl)(2hydroxyphenyl)methyl]-2,3-dihydro-4,6-benzofurandiol (4). The mass spectral data of the permethylated derivative $(4 \mathrm{M})$ are also consistent with this structure. 


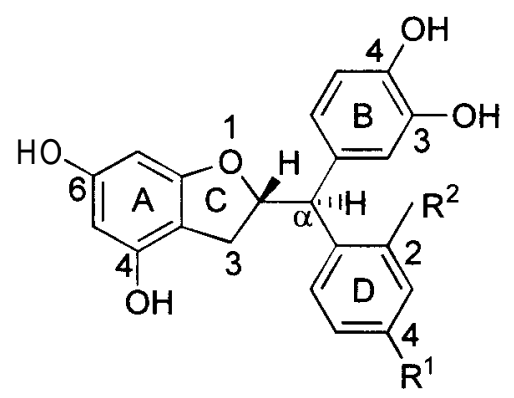

$$
\begin{aligned}
& 3 \mathbf{R}^{1}=O H ; R^{2}=H \\
& 4 \mathbf{R}^{1}=H ; R^{2}=O H
\end{aligned}
$$

The proton (Table 1) and carbon (Table 2) NMR spectra of 5 were similar to those of 3 , except that in the 'H-NMR, only one A-ring aromatic proton, a singlet at $5.86 \mathrm{ppm}$, was observed, indicating the presence of a substitutent on the A-ring. Two p-hydroxyphenyl substituents were evident from the four sets of two proton doublets at 6.61, 6.69, 6.97 and $7.09 \mathrm{ppm}$. An H-H COSY experiment showed the doublets at 6.61 and 6.97 were paired as were the doublets at 6.69 and 7.09. Further, the $\mathrm{H}-\mathrm{H}$ COSY experiment showed the two methylene protons $(\mathrm{H}-3 \mathrm{a}$ and $\mathrm{H}-3 \mathrm{~b})$ at 2.75 and $2.98 \mathrm{ppm}$ were correlated with the multiplet at $5.30 \mathrm{ppm}(\mathrm{H}-2)$ which in turn was correlated with the doublet at $3.85 \mathrm{ppm}(\mathrm{H}-\mathrm{a})$. The coupling constant $J_{2, \alpha}=8.8 \mathrm{~Hz}$ is consistent with trans-stereochemistry between $\mathrm{H}-2$ and $\mathrm{H}$-a.

An H-C HETCOR experiment showed that the two protons at 3.58 ppm were connected to a carbon at $29.0 \mathrm{ppm}$, suggesting that one of the p-hydroxyphenyl groups is linked through a methylene bridge. A COLOC experiment showed that the protons at $3.58 \mathrm{ppm}$ were correlated with the A-ring quaternary carbon as well as with one of the phydroxyphenyl groups. As was observed in the spectrum of 4 , the other phydroxyphenyl group, together with the catecholic B-ring, is attached at a benzylic carbon.

Although these NMR data and the high resolution mass spectrum established the basic structure of 5 , a question remained as to whether the p-hydroxyphenylmethane substituent was linked at C-5 or C-7 of the 
A-ring. Compound 5 was methylated with dirnethylsulfate over potassium carbonate. COSY experiments showed an elongated cross-peak between the A-ring singlet at $5.86 \mathrm{ppm}$ and the complex set of methoxyl signals suggesting that this proton was correlated with two methoxyls with similar chemical shifts. NOE DIFFERENCE experiments provided sufficient resolution to clearly show correlation of the proton singlet at $5.86 \mathrm{ppm}$ to both A-ring methoxyl signals at 3.75 and $3.79 \mathrm{ppm}$.

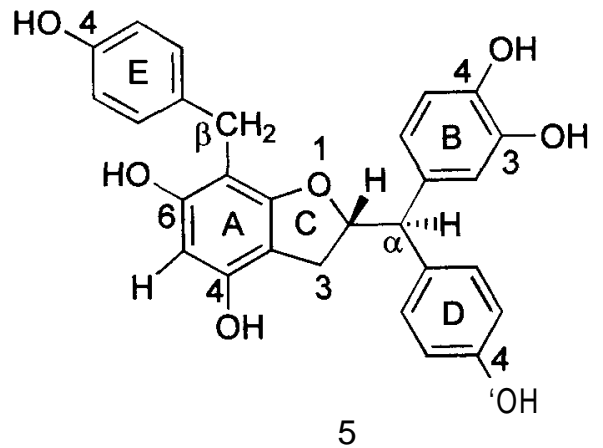

These results show that the p-hydroxyphenylrnethane substituent is located at C-7. Had substitution occurred at C-5, irradiation of the $\mathrm{H}-7$ proton would have shown correlation to only one methoxyl. These data clearly establish that the structure for this new compound is $2-[(3,4-$ dihydroxyphenyl)(4-hydroxyphenyl)methyl]-2,3-dihydro-7-(4-hydroxyphenyl)methyl-4,6-benzofurandiol (5).

The ${ }^{1} \mathrm{H}$-NMR and ${ }^{13} \mathrm{C}$-NMR spectra for 6 are summarized in Tables 1 and 2, respectively. An H-C HETCOR experiment shows that the proton doublet at $7.24 \mathrm{ppm}(2 \mathrm{H}, \mathrm{d}, \mathrm{J}=8.7 \mathrm{~Hz})$ is correlated with the carbon signal at $129.6 \mathrm{ppm}$, while the proton doublet at $6.77 \mathrm{ppm}(2 \mathrm{H}, \mathrm{d}, \mathrm{J}=\mathbf{8} .7$ $\mathrm{Hz}$ ) is correlated with the carbon signal at $115.1 \mathrm{ppm}$. The COSY spectrum shows that the proton doublets at 6.77 and $7.24 \mathrm{ppm}$ are correlated. These data are indicative of a phydroxyphenyl substituent.

The H-C HETCOR experiment further shows that the doublet at 6.36 ppm $(1 \mathrm{H}, \mathrm{d}, \mathrm{J}=2.0 \mathrm{~Hz})$ is correlated with the carbon at $113.3 \mathrm{ppm}$, the 
doublet of doublets at $6.19 \mathrm{ppm}(1 \mathrm{H}, \mathrm{dd}, \mathrm{J}=2.0,6.1 \mathrm{~Hz})$ is correlated with a carbon at about $116.5 \mathrm{ppm}$, and the doublet at $6.58 \mathrm{ppm}(1 \mathrm{H}, \mathrm{d}, \mathrm{J}=8.1$ $\mathrm{ppm}$ ) is correlated with a carbon at $114.8 \mathrm{ppm}$. In addition, the doublet at $6.85 \mathrm{ppm}(\mathrm{d}, \mathrm{J}=1.7 \mathrm{~Hz})$ is correlated to a carbon at $115.5 \mathrm{ppm}$. A higher field proton signal at $6.75 \mathrm{ppm}$ which is correlated with the carbon at $119.7 \mathrm{ppm}$ overlaps a proton signal at about $6.77 \mathrm{ppm}$ which is correlated with a carbon at $115.2 \mathrm{ppm}$. These data indicate the presence of two catechol rings. The assignment of these signals to catechol rings was substantiated by a COSY experiment.

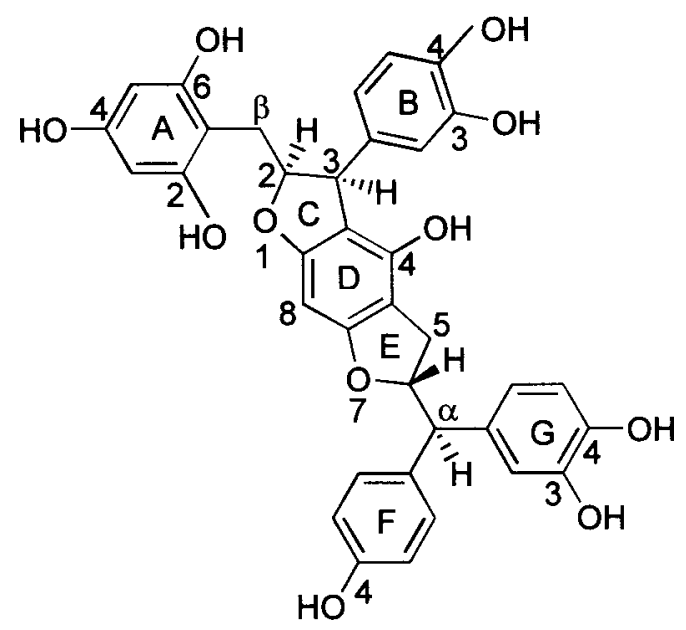

6

The two proton singlet at $6.01 \mathrm{ppm}$ is consistent with a freely rotating, symmetrical phloroglucinol ring. This is in agreement with the results of a $\mathrm{H}-\mathrm{C}$ HETCOR experiment showing that the two proton singlet $(6.01 \mathrm{ppm})$ is correlated with the carbon signal at $94.8 \mathrm{ppm}$. The HETCOR experiment further showed that the proton singlet at $5.75 \mathrm{ppm}$ is correlated with a carbon at $84.7 \mathrm{ppm}$. This proton ( $5.75 \mathrm{ppm})$ did not show correlation to any of the aliphatic protons in the COSY or HOMODEC experiments and can be assigned to a second phloroglucinolring. In addition, a COLOC experiment showed correlation between this 
proton (5.75 ppm) and the two quarternary carbons at 161.2 and 161.5 ppm that are assigned to C-7a and C-8a, respectively. The large upfield shift of the aromatic carbon from the approximate $95 \mathrm{ppm}$ normally observed for the hydrogen-substituted carbons of a phloroglucinol ring to $84.7 \mathrm{ppm}$ is consistent with the second phloroglucinol ring being part of a benzodifuran moiety.

The COSY experiment shows that the multiplet at $5.44 \mathrm{ppm}$ has strong cross peaks with the doublet at $3.99 \mathrm{ppm}(\mathrm{J}=9.7 \mathrm{~Hz})$ and the two methylene protons at about 2.71 and $3.00 \mathrm{ppm}$. This part of the spectrum is very similar to the proton coupling seen in 3 . The H-C HETCOR experiment shows that the multiplet $(5.44 \mathrm{ppm})$ is correlated with a carbon at $86.1 \mathrm{ppm}$ and the doublet at $3.99 \mathrm{ppm}$ with a carbon at $55.4 \mathrm{ppm}$. Cross peaks to the methylene protons were not observed. Importantly, the LONG RANGE COSY shows a strong cross peak between this proton (3.99 ppm) and the down field phydroxyphenyl proton doublet at 7.24 $\mathrm{ppm}$. These data are consistent with a phydroxyphenyl unit bonded together with a catechol-ring at a benzylic carbon. The coupling constant of $9.7 \mathrm{~Hz}$ for $\mathbf{J}_{6, \alpha}$ is consistent with trans-stereochemistry.

The multiplet at $4.78 \mathrm{ppm}$ is correlated with a carbon at $92.2 \mathrm{ppm}$. The LONG RANGE COSY spectrum shows this proton (4.78 ppm) has strong long range coupling with the two methylene protons at about 2.98 and $3.08 \mathrm{ppm}$ and with the doublet at $4.34 \mathrm{ppm}(\mathrm{J}=3.4 \mathrm{~Hz})$. The coupling constant of $3.4 \mathrm{~Hz}\left(\mathrm{~J}_{2,3}\right)$ is consistent with cis-stereochemistry. In addition, the doublet at $4.34 \mathrm{ppm}$ has long range coupling with the singlet at $5.75 \mathrm{ppm}$. These data indicate the proximity of the proton $(4.34 \mathrm{ppm})$ to the phloroglucinol ring of the benzodifuran moiety. In addition, the methylene protons at 2.98 and 3.08 ppm have long range coupling with the singlet at $6.01 \mathrm{ppm}$, indicating the proximity of the methylene protons to the freely rotating phloroglucinol ring. The LONG RANGE COSY experiment shows coupling between protons at 6.19 and $6.36 \mathrm{ppm}$ (assigned to catechol ring $B$ ) with the proton at $4.34 \mathrm{ppm}$, and protons at 6.75 and $6.85 \mathrm{ppm}$ (assigned to a second catechol ring $\mathrm{G}$ ) with the proton at $3.99 \mathrm{ppm}$.

The mass spectral data and the NMR data (Tables 1 and 2) show that this is the novel compound 2-(1,3,5-trihydroxyphenyl)methyl-3-(3,4- 
dihydroxyphenyl)-6-[(3,4-dihydroxyphenyl)(4-hydroxyphenyl)methyl]2,3,5,6-tetrahydrobenzo[1,2-b:5,4-b']difuran-4-ol (6).

\section{Phenolation Reactions of Catechin During Liquefaction}

These compounds were isolated from mixtures in which catechin was reacted with phenol using $\mathrm{H}_{2} \mathrm{SO}_{4}$ as the acid catalyst and using no additional solvent. TLC results show that these compounds can be formed using either a Lewis acid $\left(\mathrm{BF}_{3} \cdot 2 \mathrm{H}_{2} \mathrm{O}\right)$ or a mineral acid $\left(\mathrm{H}_{2} \mathrm{SO}_{4}\right.$ or $\mathrm{HCl})$ as the catalyst. The absolute stereochemistry of the starting compound $(+)$-catechin is known $(\mathbf{2} \mathbf{R}, \mathbf{3 S})$. If assumptions are made about the mechanisms by which these reactions occur, then conjectures can be made as to the absolute stereochemistry of the reaction products. Thus, Mitsunaga et al. ${ }^{4}$ have postulated that phenol attacks the pyran ring from the side opposite the C-3 hydroxyl with concomitant opening of the pyran ring to stereoselectively produce $\mathbf{1}$ wherein the stereochemistry is $\mathbf{2 S , 3 R}$ and the $\mathrm{H}-2$ and $\mathrm{H}-3$ protons are trans as indicated by the ${ }^{1} \mathrm{H}-\mathrm{NMR}$ spectrum.

Mitsunaga et al. then postulated that 1 undergoes dehydration and stereoselective ring closure to give 3 wherein the stereochemistry is $2 \mathbf{S}, \alpha \mathbf{R}$ and the $\mathrm{H}-2$ and $\mathrm{H}-\alpha$ protons are trans. Compounds 1 and 3 are formed in larger amount than 2 and 4 indicating preference for reactions at the para position of phenol as has been observed ${ }^{9}$ in the methylolation of phenol with formaldehyde.

Although neither p-hydroxybenzyl alcohol nor o-hydroxybenzyl alcohol were isolated, their condensation products with phenol were found among the reaction products. The presence of these products and isolation of compound 5 indicates that formaldehyde is formed during the phenolysis of catechin. The isolation of phloroglucinol and catechol shows that the aromatic rings can be cleaved from the 2-hydroxypropyl chain. It would be difficult to determine if compound 5 is produced by 1) methylolation at C-7 in the A-ring of 4 followed by condensation with the para-position of phenol, 2) by condensation of p-hydroxybenzyl alcohol at C-7 in the A-ring of 3, or 3) by condensation p-hydroxybenzyl alcohol at C-4 in the A-ring of 1 followed by dehydration and ring closure. The high mole ratio of phenol, and the isolation of the dimeric phenol 
condensation products, support one of the latter two alternatives. Condensation of phydroxybenzyl alcohol with 3 is preferred because 5 was only found after longer reaction times when 1 had already reacted to form 3. Preference for substitution at $\mathrm{C}-7$ in the A-ring of 3 is expected given the selectivity observed in the reaction of $p$-hydroxymethylphenol at C-8 of catechin. 10

The exceptional properties of $\mathbf{C}-6 / \mathbf{C}-8$ of the catechin A-ring as a nucleophile are emphasized by the isolation of compound 6 . Mole ratios of phenol to catechin were approximately $35: 1$ in these reactions. However, despite conditions favoring the reaction of phenol with catechin, reaction of 1 or 3 with catechin to give compound 6 was still observed.

It is important to recognize that, whereas (+)-catechin serves as an adequate model for reactions involving the pyran ring, more work is needed to define the reactions of polymeric flavans in which another flavan unit is attached at C-4 of the catechin C-ring. McGraw has described acid catalyzed rearrangements of flavan-4-thiobenzyl ethers 11 where protonation of $\mathrm{C}-4 \mathrm{a}$ leads to cleavage of the $\mathrm{C}-4$ to $\mathrm{C}-4 \mathrm{a}$ bond with subsequent attack of the carbocation on the B-ring to give ring closure to indane derivatives. This reaction also leads to cleavage of the ether linkage releasing pholoroglucinol. Although pholoroglucinol was observed as a product in the phenolysis of catechin, we did not find indanes as were described by McGraw. However, acetic acid-catalyzed reactions of flavan-4-phloroglucinol adducts exhibit dehydration reactions with ring closure to benzofuran derivatives similar to those reported here. 12

Normally, the compounds corresponding to lower $\mathbf{R}_{\boldsymbol{f}}$ on TLC have longer retention times on a Sephadex LH-20 column. Compounds with a $\mathbf{R}_{\mathbf{f}}$ lower than that of catechin are presumably condensed products, and have molecular weights greater than that of catechin. After $30 \mathrm{~min}$ of reaction at $40{ }^{\circ} \mathrm{C}$, approximately $56 \%$ of the reaction products had a $\mathbf{R}_{\mathbf{f}}$ less than that of catechin $\left(R_{f}=0.42\right)$. Increasing the reaction time to 240 min, increased the percentage to $63 \%$. This data suggests that the amount of phenolated catechin produced increases with increasing reaction time. This result is in agreement with the observations by Ono and Inoue ${ }^{2}$ on the phenolation of whole bark who found that the amount 
of higher molecular weight products increased with increased reaction time for phenolation.

\section{$\underline{\text { CONCLUSIONS }}$}

From reactions of catechin with phenol using mineral acid catalysts, we have isolated ten products, four of which are novel compounds reported here for the first time while two others were described earlier as major products of the reaction of catechin with phenol in benzene or xylene solvents using $\mathrm{BF}_{3} \cdot 2 \mathrm{H}_{2} \mathrm{O}$ as a catalyst. Based on the structures of the isolated compounds, it was possible to postulate a scheme whereby these compounds were formed. During phenolation of catechin, phenol (either para or ortho to the phenolic hydroxyl) reacts at C-2 of the catechin opening the pyran ring. The phenolated catechin also further condenses with 4-hydroxymethylphenol which is presumably formed by liberation of formaldehyde from destruction of the the pyran ring as evidenced by the isolation of small amounts of phloroglucinol, catechol, and both 4-(hydroxyphenyl)(4-hydoxyphenyl)methane and 4-(hydroxyphenyl)(2-hydroxyphenyl)methane from these reactions. It is important to note the exceptional nucleophilicity of the phloroglucinolic A-ring in catechin as was shown by isolation of a reaction product in which catechin competes with phenol although molar ratios of phenol to catechin are approximately $35: 1$. Phenolation occurs readily using phenol only as a solvent and mineral acids as a catalyst. No doubt, similar reactions occur in the phenolation of tannins when reacting oligomeric or polymeric flavanoids or whole bark.

\section{EXPERIMENTAL}

Phenolation Reactions

Small scale reactions: (+)-Catechin hydrate (Sigma Chemical Inc. ${ }^{a}$ ) ( $0.16 \mathrm{mmole})$ was reacted with phenol $(20 \mathrm{mmole})$ using $0.5 \mathrm{mmol}$ of

\footnotetext{
a The use of trade, firm, or corporation names is for the information of the reader. Such use does not constitute an official endoresement or approval by the USDA of any product or service to the exclusion of others that may be suitable.
} 
either $\mathrm{H}_{2} \mathrm{SO}_{4}, \mathrm{HCl}$, or $\mathrm{BF}_{3}-2 \mathrm{H}_{2} \mathrm{O}$ as a catalyst. Reactions were conducted at $40^{\circ} \mathrm{C}$ for either 30 or 240 min. Reactions were carried out in $10 \mathrm{~mL}$ glass ampoules in either xylene $(1 \mathrm{~mL})$ or benzene $(1 \mathrm{~mL})$ as solvents, or without any additional solvent. Reactions were also conducted using these condition but without any added phenol.

Large scale reactions: (+)-Catechin hydrate (8 mmole) was reacted with phenol (1 mole) using $25 \mathrm{mmol}$ of $\mathrm{H}_{2} \mathrm{SO}_{4}$ as the catalyst. No additional solvents were used.

\section{$\underline{\text { TLC Analysis }}$}

Reaction products were analyzed on TLC plates coated with $0.2 \mathrm{~mm}$ of 60F254 silica gel (EM Industries Inc., Germany). The developing solvent was toluene/ethyl acetate/acetic acid (5:4:1). Spots were visualized under UV light and by spraying with vanillin- $\mathrm{HCl}$. Preparative TLC was conducted using the same conditions, except that the plates were coated with $2 \mathrm{~mm}$ of 60F254 silica gel. Compounds 1,2, and phloroglucinol were isolated from a reaction conducted at $40{ }^{\circ} \mathrm{C}$ for 30 minutes. Compounds 3, 4, and (4-hydroxypheny)(4-hydroxyphenyl)methane were isolated from a reaction conducted at $40{ }^{\circ} \mathrm{C}$ for 240 minutes. _Catechol and (4-hydroxyphenyl)(2-hydroxyphenyl)methane were isolated from a reaction conducted at $140{ }^{\circ} \mathrm{C}$ for 60 minutes.

\section{Purification of Compounds}

The reaction products were dissolved in 95\% ethyl alcohol and separated on a Sephadex LH-20 column by elution with $95 \%$ ethyl alcohol where $10 \mathrm{~mL}$ fractions were collected. TLC was used to monitor elution of the reaction components. Fractions having similar composition were combined and the solvent removed by evaporation. The combined fractions were rechromatographed on a Sephadex LH-20 column, eluting with methanol/water (1: 1 by volume) where $5 \mathrm{~mL}$ fractions were collected. TLC was used to monitor the separation of components. Fractions having similar composition were combined and the solvent removed by evaporation. Final purification of the isolated compounds was accomplished using preparative-scale TLC. 
NMR Analysis

NMR spectra of samples in $\mathrm{CD}_{3} \mathrm{OD}$ were obtained on a Bruker AC-300 spectrometer using standard pulse sequences for proton, carbon, COSY, HETCOR, COLOC, HOMODEC, and NOE experiments.

\section{Mass Spectral Analysis}

Low resolution electron impact (EIMS) and chemical ionization mass spectra (CIMS) were recorded on a Finnigan Model 4500 mass spectrometer. Low resolution electron impact mass spectra (EIMS), high resolution electron impact mass spectra (HRMS), fast atom bombardment mass spectroscopy (FAB-MS), and high resolution fast atom bombardment mass spectroscopy (HRFAB-MS) were obtained by the Chemistry Instrumentation Center, Department of Chemistry, University of Wisconsin-Madison using a Kratos MS-80RFA with DS55/DS90.

\section{2-[3-(3,4-Dihydroxyphenyl)-2-hydroxy-3-(4-hydroxyphenyl)propyl]-1,3,5-} benzenetriol (1).

The synthesis and isolation of this compound has been described previously. ${ }^{4-6}$ Compound 1 (122 $\mathrm{mg}$ ) was obtained using the separation methods described above. TLC: $\mathbf{R}_{\mathbf{f}}=0.42$. 'H-NMR and ${ }^{13} \mathrm{C}-\mathrm{NMR}$ data are tabulated in Tables 1 and 2, respectively. Ammonia CIMS m/z (relative intensity): $402\left(\mathrm{M}^{+}+\mathrm{NH}_{4}, 2.8\right), 384\left(\mathrm{M}^{\prime}, 1.5\right), 367\left(\mathrm{M}^{+}-\mathrm{H}_{2} \mathrm{O}+\mathrm{H}\right.$, 100). EIMS m/z (relative intensity): $384\left(\mathrm{M}^{\prime}, 0.2\right), 366\left(\mathrm{M}^{+}-\mathrm{H}_{2} \mathrm{O}, 4\right), 256$ (5), 240 (IO), 230 (II), 229 (17), 228 (100), 226 (IO), 216 (20), 215 (24), 197(8), 181 (21), 152 (12), 139 (12), $126(20), 123(33), 110$ (65), 107 (73), 94 (91), 77 (24). HRMS m/z: $366.1118\left(\mathrm{M}^{+}-\mathrm{H}_{2} \mathrm{O}\right) ; \mathrm{C}_{21} \mathrm{H}_{18} \mathrm{O}_{6}$ requires 366.1103.

\section{2-[3-(3,4-Dihydroxyphenyl)-2-hydroxy-3-(2-hydroxyphenyl)propyll-1,3,5- benzenetriol (2).}

Compound $2(11 \mathrm{mg})$ was obtained using the separation methods described above. TLC: $\mathbf{R}_{\mathbf{f}}=0.46$. 'H-NMR and ${ }^{13} \mathrm{C}-\mathrm{NMR}$ data are tabulated in Tables 1 and 2, respectively. FAB-MS $\mathbf{m} / \mathbf{z}$ (relative intensity): 384 (M', 12). EIMS m/z (relative intensity): $366\left(\mathbf{M}^{+}-\mathrm{H}_{2} \mathrm{O}, 1.5\right)$, 256 (2), 240 (12), 230 (54), 228 (62), 229 (12), 226 (83), 216 (18), 197 
(20), 181 (14), $152(24), 140(27), 139(29), 126(85), 124(32), 123$ (100), 110 (66), 107 (62), 94 (39), 77 (31), 76 (23). HRMS m/z: $366.1048\left(\mathbf{M}^{+}-\right.$ $\left.\mathrm{H}_{2} \mathrm{O}\right) ; \mathrm{C}_{21} \mathrm{H}_{18} \mathrm{O}_{6}$ requires 366.1103 .

2-[(3,4-Dihydroxyphenyl)(4-hydroxyphenyl)methyl]-2,3-dihydro-4,6benzofurandiol (3).

The synthesis and isolation of this compound has been previously described. ${ }^{4-7}$ Compound $3(232.5 \mathrm{mg})$ was obtained using the separation methods described above. TLC: $R_{f}=0.57$. ' $H-N M R$ and ${ }^{13} \mathrm{C}$-NMR data are tabulated in Tables 1 and 2, respectively.

\section{2-[(3,4-Dihydroxyphenyl)(2-hydroxyphenyl)methyl]-2,3-dihydro-4,6-} benzofurandiol (4).

Compound $4(22 \mathrm{mg})$ was obtained using the separation methods described above. TLC: $R_{f}=0.65$. 'H-NMR and ${ }^{13} \mathrm{C}$-NMR data are tabulated in Tables 1 and 2, respectively. Compound $4(10 \mathrm{mg})$ was dissolved in acetone $(10 \mathrm{~mL})$. Dimethyl sulfate $(0.1 \mathrm{~mL})$ and $\mathrm{K}_{2} \mathrm{CO}_{3}(1.0$ g) were added and the mixture refluxed for $17 \mathrm{hrs}$. A single major product (4M) was isolated by preparative TLC. EIMS m/z (relative intensity): 437 (15), $436\left(\mathbf{M}^{+}, 54\right), 434(6), 270(14), 259(14), 258(81), 257$ (100), 179 (52), $178(31), 164$ (12), 152 (8), 151 (67), 121 (IO), 107 (5), 91 (8), 83 (8), 77 (5). HRMS m/z: $436.1874\left(\mathrm{M}^{\prime}\right) ; \mathrm{C}_{26} \mathrm{H}_{28} \mathrm{O}_{6}$ requires 436.1886.

\section{2-[(3,4-Dihydroxyphenyl)(4-hydroxyphenyl)methyl]-2,3-dihydro-7-(4-} hydroxyphenyl)methyl-4,6-benzofurandiol (5).

Compound $5(82 \mathrm{mg})$ was obtained using the separation methods described above. TLC: $R_{\mathrm{f}}=0.54$. 'H-NMR and ${ }^{13} \mathrm{C}-\mathrm{NMR}$ data are tabulated in Tables 1 and 2, respectively. Compound $5(40 \mathrm{mg})$ was dissolved in acetone $(20 \mathrm{~mL})$. Dimethyl sulfate $(0.25 \mathrm{~mL})$ and $\mathrm{K}_{2} \mathrm{CO}_{3}(1.5$ g) were added and the mixture refluxed for $17 \mathrm{hrs}$. A single product (5M) was isolated by preparative TLC. EIMS m/z (relative intensity): 556 (M', 4), 554 (7), 432 (6), 352 (14), 336 (15), 321 (18), 298 (17), 295 (18), 270 (18), 258 (49), 257 (58), 241 (II), 227 (18), 151 (19), 122 (49), 121 (100), 107 (16), 91 (21), 85 (II), 77 (20). HRMS m/z: $556.2466\left(\mathrm{M}^{+}\right) ; \mathrm{C}_{34} \mathrm{H}_{36} \mathrm{O}_{7}$ requires 556.2461 . 
2-(1,3,5-Trihydroxyphenyl)methyl-3-(3,4-dihydroxyphenyl)-6-[(3,4dihydroxyphenyl)(4-hydroxyphenyl)methyll-2,3,5,6-tetrahydrobenzo[1,2-b:5,4-b']difuran-4-ol (6).

Compound $6(150 \mathrm{mg})$ was obtained using the separation methods described above. TLC: $\mathbf{R}_{\mathbf{f}}=0.33$. ${ }^{1} \mathrm{H}-\mathrm{NMR}$ and ${ }^{13} \mathrm{C}$-NMR data are tabulated in Tables 1 and 2, respectively. EIMS $\mathbf{~} / \mathbf{z}$ (relative intensity): 272 (3), 256 (2), 240 (4), 228 (93), 216 (65), 199 (12), 181 (13), 150 (12), 139 (13), 126 (86), 123 (48), 110 (100), 107 (51). HRFAB-MS m/z: $638.1783\left(\mathrm{M}^{+}\right) ; \mathrm{C}_{36} \mathrm{H}_{30} \mathrm{O}_{11}$ requires 638.1788. Compound $6(10 \mathrm{mg})$ was dissolved in acetone $(15 \mathrm{~mL})$. Dimethyl sulfate $(0.2 \mathrm{~mL})$ and $\mathrm{K}_{\mathbf{2}} \mathrm{CO}_{3}(1.0$ g) were added and the mixture refluxed for $17 \mathrm{hrs}$. A single major product was isolated by preparative TLC. Ammonia $\mathrm{CIMS} \mathrm{m/z} \mathrm{(relative} \mathrm{intensity):}$ $765\left(\mathbf{M}^{+}+\mathrm{H}, 100\right), 764\left(\mathbf{M}^{+}\right)$.

\section{Phloroglucinol.}

Phloroglucinol (11 mg) was obtained using the separation methods described above. TLC: $\mathbf{R}_{\mathbf{f}}=0.70$. 'H-NMR, ppm: 5.78 (s; H-2, H-4, H-6). ${ }^{13}$ C-NMR, ppm: 95.5 (C-2, C-4, C-6), 160.1 (C-I, C-3, C-5). H-C HETCOR NMR: proton singlet at $5.78 \mathrm{ppm}$ is correlated with carbon signal at $95.5 \mathrm{ppm}$. EIMS m/z (relative intensity): $127(35), 126\left(\mathrm{M}^{+}\right.$, 100), 110-(6), 85 (21). HRMS m/z: $126.0314\left(\mathrm{M}^{\prime}\right) ; \mathrm{C}_{6} \mathrm{H}_{6} \mathrm{O}_{3}$ requires 126.0317.

\section{Catechol.}

Catechol (5 mg) was obtained using the separation methods described above. TLC: $\mathbf{R}_{\mathbf{f}}=0.83 .{ }^{1} \mathrm{H}-\mathrm{NMR}: 6.67 \mathrm{ppm}(\mathrm{m} ; \mathrm{H}-4, \mathrm{H}-5)$ and 6.77 ppm (m; H-3, H-6). ${ }^{13} \mathrm{C}-\mathrm{NMR}: 121.0$ ppm (C-4, C-5), 116.4 pm (C-3, C-6), 146.2 ppm (C-I, C-2). H-C HETCOR NMR: proton multiplets at 6.67 and $6.77 \mathrm{ppm}$ are correlated with carbon resonances at 116.4 and $121.0 \mathrm{ppm}$, respectively. EIMS m/z (relative intensity): $111(9), 110\left(\mathbf{M}^{+}\right.$, 100), 92 (8). HRMS m/z: $110.0375\left(\mathbf{M}^{+}\right) ; \mathrm{C}_{6} \mathrm{H}_{6} \mathrm{O}_{2}$ requires 110.0368.

\section{(4-Hydyoxyphenyl)(4-hydroxyphenyl)methane.}

The title compound $(50.1 \mathrm{mg})$ was obtained using the separation methods described above. TLC: $\mathbf{R}_{\mathbf{f}}=0.85$. 'H-NMR, ppm: $3.77(2 \mathrm{H}, \mathbf{s}$; $\mathrm{H}-\mathrm{a}) ; 6.67(4 \mathrm{H}, \mathrm{d}, \mathrm{J}=8.5 \mathrm{~Hz}$; H-A3, H-A5, H-B3, H-B5); 6.95 (4H, d, J = 
8.5 Hz; H-A2, H-A6, H-B2, H-B6 ). ${ }^{13}$ C-NMR, ppm: 41.0 (C-a); 134.2 (C-Al, C-BI); 130.7 (C-A2, C-A6, C-B2, C-B6 ); 116.1 (C-A3, C-A5, C-B3, C-B5 ); 156.5 (C-A4, C-B4). H-C HETCOR NMR: proton doublets at 6.67 ppm and $6.95 \mathrm{ppm}$ are correlated with the carbon resonances at 116.1 and $130.7 \mathrm{ppm}$, respectively. The proton singlet at $3.77 \mathrm{ppm}$ is correlated with the carbon resonance at $41.0 \mathrm{ppm}$. COSY NMR: proton doubles at 6.67 and $6.95 \mathrm{ppm}$ are correlated. EIMS $\mathrm{m} / \mathbf{z}$ (relative intensity): 201 (10), $200\left(\mathbf{M}^{+}, 97\right), 199(10), 183(9), 181(8), 107$ (100), 94 (19), 77 (13).

HRMS m/z: 200.0840 (M'); $\mathrm{C}_{13} \mathrm{H}_{12} \mathrm{O}_{2}$ requires 200.0837.

\section{(4-Hydyoxyphenyl)(2-hydroxyphenyl)methane.}

The title compound ( $6 \mathrm{mg}$ ) was obtained using the separation methods described above. TLC: $\mathbf{R}_{\mathbf{f}}=0.92$. ${ }^{1} \mathrm{H}-\mathrm{NMR}, \mathrm{ppm}$ : $3.82(2 \mathrm{H}, \mathrm{s}$; $\mathrm{H}-\mathrm{a}) ; 6.64$ (2H, d, J = $8.6 \mathrm{~Hz}$; H-A3, H-A5); 6.72 (1H, m; H-B5); $6.76(1 \mathrm{H}$, d, J = $8.1 \mathrm{~Hz} ; \mathrm{H}-\mathrm{B} 3) ; 6.94$ (1H, d, J = $7.7 \mathrm{~Hz} ; \mathrm{H}-\mathrm{B} 6) ; 6.98$ (1H, m; H-B4); $7.01\left(2 \mathrm{H}, \mathrm{d}, \mathrm{J}=8.6 \mathrm{~Hz}\right.$; H-A2,. H-A6). ${ }^{13} \mathrm{C}-\mathrm{NMR}, \mathrm{ppm}: 35.7$ (C-a); 116.1 (C-A3, C-A5, C-B3); 120.5 (C-B5); 128.0 (C-B4); 130.4 (C-BI); 130.7 (C-A2, C-A6);131.3 (C-B6); 133.6 (C-Al); i56.1 (C-B2); 156.3 (C-A4). $\mathrm{H}-\mathrm{C}$ HETCOR NMR: shows the four aromatic protons at $6.72-6.94 \mathrm{ppm}$ are correlated with the carbon resonance at 116.1, 128.0, 120.5 and 131.3 ppm, respectively. EIMS m/z (relative intensity): 201 (14), 200 (M', 81), 199 (M, 16), 181 (10), 107 (100), 94 (35), 77 (9). HRMS m/z: $200.0826\left(M^{\prime}\right), \mathrm{C}_{13} \mathrm{H}_{12} \mathrm{O}_{2}$, requires 200.0837 .

\section{REFERENCES}

1. M. A. E. Santana, M. G. D. Baumann and A. H. Conner, Holzforchung, 49, 146-152 (1995).

2. H. K. Ono and A. Inoue, In: Adhesives and Bonded Wood Products. C. Y. Hse, B. Tomita and S. J. Branham (Eds). Forest Products Society Proceeding No. 4735, pp. 330-343, 1994.

3. S. Pu, M. Yoshioka, Y. Tanihara, and N. Shiraishi, In: Adhesives and Bonded Wood Products. C. Y. Hse, B. Tomita and S. J. Branham (Eds). Forest Products Society Proceeding No. 4735, pp. 344-355, 1994. 
4. T. Mitsunaga and I. Abe, Mokuzai Gakkaishi, 38, 565-592 (1992).

5. T. Mitsunaga, I. Abe, and T. Nogami, Mokuzai Gakkaishi, 39, 328332 (1993).

6. T. Mitsunaga, I. Abe, and S. Ohara, Mokuzai Gakkaishi, 38, 100-106 (1994)

7. W. Peng, A. H. Conner, and R. W. Hemingway, In: Wood Adhesives 1995. A. W. Christiansen and A. H. Conner (Eds.). Forest Products Society Proceeding No. 7296, pp. 247-253, 1995.

a. G. C. Levy and G. L. Nelson, Carbon-13 Nuclear Magnetic Resonance for Organic Chemists, Wiley-Interscience, New York, NY, 1972.

9. G. W. McGraw, L. L. Landucci, S. Ohara, and R.W. Hemingway, J. Wood Chem. \& Technol., 9(2), 201-217 (1969)

10. G. W. McGraw, In: Chemistry and Significance of Condensed Tannins. R. W. Hemingway, J. J. Karchesy and S. J. Branham (Eds.). Plenum Press, New York, NY, pp. 227-246, 1969.

11. G. W. McGraw, J. P. Steynberg and R. W. Hemingway, Tetrahedron Letters, 34(6), 987-990 (1993).

12. P. J. Steynberg, J. P. Steynberg, R. W. Hemingway, D. Ferreira, and G. W. McGraw, J. Chem. Soc., Perkin Transactions 1 (in press). 